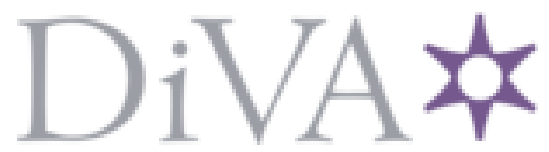

http://www.diva-portal.org

This is the published version of a paper published in European Journal of Cancer Care.

Citation for the original published paper (version of record):

Udo, C., Lövgren, M., Lundquist, G., Axelsson, B. (2017)

Palliative care physicians' experiences of end-of-life communication: A focus group study.

European Journal of Cancer Care

https://doi.org/10.1111/ecc.12728

Access to the published version may require subscription.

N.B. When citing this work, cite the original published paper.

Permanent link to this version:

http://urn.kb.se/resolve?urn=urn:nbn:se:du-25637 


\title{
Palliative care physicians' experiences of end-of-life communication: A focus group study
}

\author{
C. Udo PhD, MSW, Senior Lecturer ${ }^{1,2}$ (D) | M. Lövgren PhD, RN, Associate Professor ${ }^{3,4,5}$ | \\ G. Lundquist MD, Physician ${ }^{2}$ | B. Axelsson MD, Senior Lecturer ${ }^{6}$
}

${ }^{1}$ School of Education, Health and Social Studies, Dalarna University, Falun, Sweden

${ }^{2}$ CKF, Centre for Clinical Research Dalarna, County Council of Dalarna, Falun, Sweden

${ }^{3}$ The Department of Health Care Sciences, Ersta Sköndal University College, Stockholm, Sweden

${ }^{4}$ Paediatric Oncology and Haematology, Department of Women's and Children's Health, Karolinska Institutet, Karolinska University Hospital, Stockholm, Sweden

${ }^{5}$ Childhood Cancer Research Unit, Astrid Lindgren Children's Hospital, Stockholm, Sweden

${ }^{6}$ Research Unit Östersund Hospital, Department of Radiation Sciences,

Umeå University, Umeå, Sweden

\section{Correspondence}

Camilla Udo, School of Education, Health and Social Studies, Dalarna University, Falun, Sweden.

Email: cud@du.se

Funding information

This study was funded by grants from the Centre for Clinical Research (CKF), County

Council of Dalarna, Sweden
The aim of this study was to explore palliative home care physicians' experiences regarding end-of-life breakpoint communication (BPC). This is a qualitative study where focus group interviews were conducted and analysed using qualitative content analysis. The results show that the participants saw themselves as being responsible for accomplishing BPC, and they were convinced that it should be regarded as a process of communication initiated at an early stage, i.e. proactively. However, BPC was often conducted as a reaction to the patient's sudden deterioration or sometimes not at all. The barriers to achieving proactive BPC included physicians' uncertainty regarding the timing of BPC, primarily due to difficulties in prognostication in terms of time of death, and uncertainty as to what BPC should include and how it should best be approached. Furthermore, there was insufficient documentation regarding previous BPC, which impeded proactive BPC. Although our study shows that physicians are ambitious when it comes to the communication of information to patients and families, there is a need for further training in how to conduct BPC and when to initiate the BPC process. Furthermore, there should be documentation that different professionals can access as this would appear to facilitate a proactive BPC process.

\section{KEYWORDS}

communication, end of life, palliative care, physicians

\section{1 | INTRODUCTION}

Palliative care should be introduced early in the disease trajectory to enable advanced care planning, thus affirming life and resulting in dying being regarded as a natural part of life (WHO, 2002). Planning endof-life care involves communication among professionals and patients and often the patient's family. Through different phases of a disease, every patient is entitled to receive understandable information, to be given the opportunity to ask questions and to discuss his/her prognosis and medical condition (Walczak, Butow, Bu, \& Clayton, 2016; Worldwide Palliative Care Alliance, 2014). This is equally important in the approach towards death so that the patient has opportunity both to express his/her individual preferences regarding care and treatment as well as to achieve as high a quality of life as possible, even when close to death (Andreassen, Neergaard, Brogaard, Skorstengaard, \& Jensen, 2015; Schou-Andersen, Ullersted, Jensen, \& Neergaard, 2016). However, numerous studies show that communication between physicians and patients in general is not optimal, despite the fact that both patients and their families find communication about, for example, prognosis to be one of the most important aspects of care at the end of life (Diamond, Corner, De Rosa, Breitbart, \& Applebaum, 2014; Evans et al., 2014; Horlait, Chambaere, Pardon, Deliens, \& Van Belle, 2016; Nedjat-Haiem et al., 2017; Winner, Wilson, Yahanda, Gani, \& Pawlik, 2016). 
In Sweden, end-of-life communication between physician and patient when the patient is transitioning from the early palliative care phase to the late palliative care phase and when death is imminent is often conceptualised as breakpoint communication (BPC): this is the concept we use in this study. When further disease-directed treatments are deemed futile, BPC provides an opportunity for the patient to receive information about, and discuss the hard reality of, ending treatment. BPC should be conducted, at the latest, when the main goal of treatment transitions from the prolongation of life to the relieving of symptoms, and when death is inevitable in the foreseeable future (The Swedish Government Official Report, SOU 2001:6; The Swedish National Board of Health and Welfare, 2007). The concept of BPC was introduced at a national level by The Swedish Register of Palliative Care and The Swedish National Board of Health and Welfare in 2007 in an attempt to systemise the way in which the patient is informed about the different goals of care in end-of-life care compared to earlier palliative care (The Swedish National Board of Health and Welfare, 2007; The Swedish Register of Palliative Care, 2007). Although the concept of BPC has not been established internationally, the concept itself, i.e. end-of-life communication that includes information and planning, is well-recognised worldwide by clinicians who work with severely ill and dying patients.

Empathetic and respectful BPC containing clear and honest information about the transition to end-of-life care is crucial for both the patient and the family in several respects. For example, Lundquist, Rasmussen, and Axelsson (2011) found that informed patients are more likely to die in their preferred place than those who are uninformed. In addition, informed patients have parenteral drugs prescribed as needed to a greater extent. Furthermore, the same study found that it is more common for informed patients' families to be offered bereavement support (Lundquist et al., 2011).

Individually adapted information about the severity of the situation is crucial at the final stage of life so that the dying patient and his/her family are given the opportunity to set priorities and prepare as much as possible physically, emotionally, socially and existentially for what lies ahead (Clayton, Butow, Arnold, \& Tattersall, 2005; Clayton et al., 2008; Dy, Apostol, Martinez, \& Aslakson, 2013; Miccinesi, Bianchi, Brunelli, \& Borreani, 2012; Wright et al., 2008). For there to be time to address these priorities and to make preparations, information must be communicated in a timely manner. However, studies show that information is often conveyed too late, making it impossible for the patient and family to express their care preferences, such as preferred place of death (cf. Clayton et al., 2005; Neergaard et al., 2011; Laryionava, Heussner, Hiddemann, \& Winkler, 2015; Pfeil, Laryionava, Reiter-Theil, Hiddemann, \& Winkler, 2015). Currently, BPC in Sweden is often initiated late, possibly only a few days before death, making it difficult to include the patient in decision making regarding medical treatments and care goals (Lundquist et al., 2011).

Despite the studies highlighting the importance of communicating information regarding deterioration in a timely manner, this often does not happen. For BPC to be initiated and for the patient to be given the opportunity to communicate with the physician providing the treatment, more needs to be learnt about this specific type of communication. The physician is medically responsible for providing a diagnosis when disease-directed treatment is unlikely to prolong life and when palliative end-of-life care is optimal. Since the responsibility includes communicating this information, it is important to explore the physicians' experiences of BPC so as to understand their view of the process and so as to learn how BPC can be supported and initiated.

\section{2 | AIM}

The aim of this study was to explore palliative home care physicians' experiences regarding end-of-life BPC.

\section{3 | METHODS}

\section{1 | Design}

This was a qualitative study in which focus group interviews were conducted and analysed using qualitative content analysis (Krippendorff, 2013). Focus group discussions were the method of choice because they have the potential to engage group members in a dynamic discussion, thus providing rich information (Morgan, 1997).

\section{2 | Settings and participants}

This study was conducted in three different regions in Sweden, two rural and one urban, in which specialised palliative home care with multi-professional teams was being offered. The teams provided care around the clock, and all teams had access to backup wards. Although some teams (those in the rural areas) had at some point enrolled a patient under the age of 18 for a variety of reasons, they almost exclusively cared for adults. All physicians employed in the palliative home care teams at the time of the study received written and oral information about the study and were invited to participate. The physicians of the palliative home care teams available at the time of the focus group discussions all participated in the study. The participants ( $n=18)$ included both men $(n=11)$, and women $(n=7)$, and they had $1-18$ years (median $=4$ years) of experience working as physicians in palliative care.

\section{3 | Data collection}

In 2015, four focus group discussions with 4-6 participants in each group, and one individual interview (one participant could not participate in the focus group interview as planned and was therefore interviewed individually) were conducted and led by the first and second authors. Different opinions exist regarding the suitable number of participants for a focus group. Some suggest no fewer than 5 (Jamieson \& Williams, 2003), whereas others believe that 4-6 participants is optimal for conducting a focus group interview (Wibeck, 2010). In our study, the number of participants was suitable for the aim. The 
TABLE 1 Examples from the analysis process

\begin{tabular}{|c|c|c|}
\hline Condensed meaning units & Codes & Categories \\
\hline $\begin{array}{l}\text { BPC defines a different kind of dialogue than one of the usual conversations. Whether I } \\
\text { decide to have the BPC in advance or it happens spontaneously does not matter, but it tells } \\
\text { colleagues somehow that now we have had this heavy dialogue. It does not really matter } \\
\text { what it is called, but it's a term that defines the difficult and not the usual conversation }\end{array}$ & $\begin{array}{l}\text { A different and difficult } \\
\text { type of dialogue }\end{array}$ & $\begin{array}{l}\text { Challenged by the concept } \\
\text { and content of BPC }\end{array}$ \\
\hline $\begin{array}{l}\text { When the patient is, what can I say?... moving from one phase to another, getting better } \\
\text { or getting worse... or when the patient is moved from home to hospital, from home to } \\
\text { palliative ward, and finally when the patient dies, these are all breakpoints where we } \\
\text { must inform the patient what we do now, and discuss the next step }\end{array}$ & $\begin{array}{l}\text { Ongoing individualised } \\
\text { information }\end{array}$ & Experiences of proactive BPC \\
\hline $\begin{array}{l}\text { Am I doing it right? Is this the right time? Was it wrong to conduct BPC now? What } \\
\text { should I do and how should I do it? }\end{array}$ & Uncertainty & Uncertainty affecting BPC \\
\hline
\end{tabular}

interaction between the participants in the focus groups motivated the choice of method for data collection. The participants were asked to discuss their BPC experiences with one another and were asked by the group leader to discuss the care in more detail, to discuss further examples of similar situations or to reflect upon how they felt and reacted in those situations; they were also asked how they perceived and dealt with the patients' reactions in the described situations. All of the discussions were tape-recorded, lasted between 45 and 80 min and were transcribed verbatim.

\subsection{Data analysis}

The transcribed text was analysed using qualitative content analysis (Krippendorff, 2013). The content analysis was found to be appropriate for the aim and the data, and allowed the analysis to move from a text-close analysis to a more interpretative level if necessary. All of the interviews were compiled as one and read as a whole several times by the first author so that a first impression could be gained before they were discussed with the second author. The first author then identified meaning units, which consisted of text passages with similar meaning, and discussed them with the second author before starting the work of labelling these meaning units with codes. The codes consisted of labels that were close to the participants' original descriptions. The codes were checked back to the meaning units several times by the first and second authors before being grouped together based on similarities in content and then being abstracted further into categories. The steps in the analysis process were continuously discussed between the first and the second authors in an effort to reach transparency and to deal with pre-understanding so that it did not steer the analysis. The authors shared critical reflections, compared the codes and found similarities and differences that could categorise the data. Before the categories were final and agreed upon by all of the authors, they were discussed, compared and somewhat revised (Table 1).

\section{5 | Ethical considerations}

This study was approved by the Regional Ethical Committee in Umeå (Dnr 2014-216-32M and 09-022M). All of the participants provided their written consent. They were ensured their confidentiality and were informed that participation in the study was voluntary.

\section{RESULTS}

In the focus group discussions, the participants shared experiences of BPC. The discussions were rich and in-depth in all of the focus groups. Similar issues were raised in the individual interview as well as in the focus groups. In the analysis, three categories were identified: challenged by the concept and content of $B P C$, experiences of proactive BPC and uncertainty affecting BPC. These categories are further described below; the categories are illustrated in Table 2 with verbatim quotations from the focus group discussions.

\subsection{Challenged by the concept and content of BPC}

BPC was described as being a concept used in discussions with other professionals. The concept of BPC was not utilised in communication with patients. The participants expressed the fact that there was a need for a shared concept of dialogue about ending treatment, e.g. oncologic treatment, and information about imminent death so that it could be discussed among professionals. However, the current concept of BPC was criticised by many of the participants, who found it misleading since it indicates there to be one clear occasion only, i.e. one obvious breakpoint, at which to provide information, something that none of the participants felt was the case (Q1). Instead, they described how $B P C$ was best when based on the continuous communication of several informative discussions with the patient and his/her family that is initiated early in the patient's disease trajectory. Although the participants emphasised the fact that an established concept was important in the facilitation of discussions between professionals, they experienced a lack of consensus and a lack of deep understanding regarding the actual content of BPC and the way it could best be conducted. For some participants, this tied with feelings of frustration when they felt "forced" to click in a check-box in the Swedish National Register of Palliative Care (Q1) or to make a note in the patient's journal that BPC had taken place without having to document anything about the content. Sometimes the participants could read in a patient's journal that there had been previous BPC with another physician in another unit (sometimes not a palliative care unit). However, with no documentation regarding the content or the way the patient was coping, it was particularly difficult to continue the process of BPC. The participants mentioned that BPC 


\begin{tabular}{|c|c|c|}
\hline & 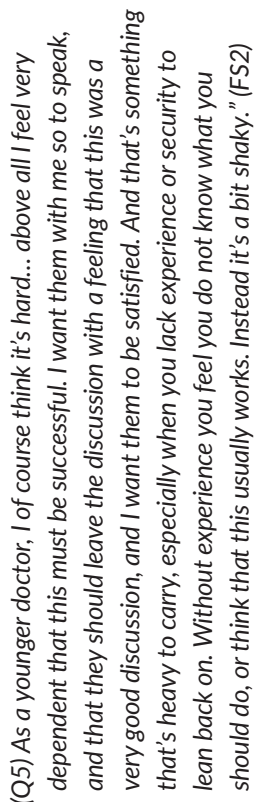 & 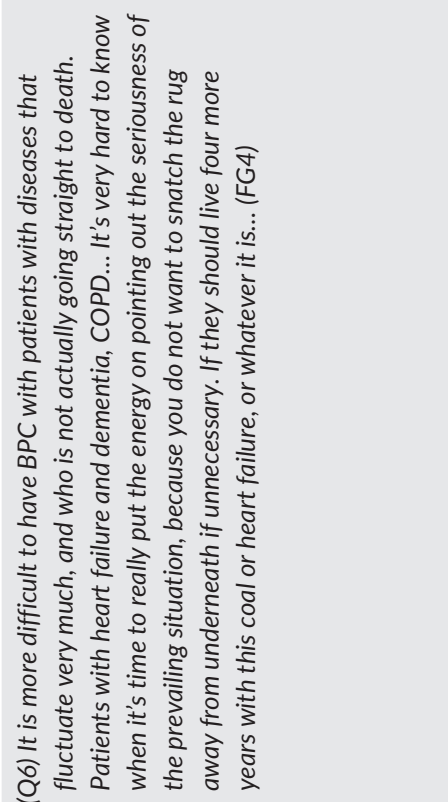 \\
\hline 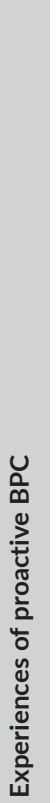 & 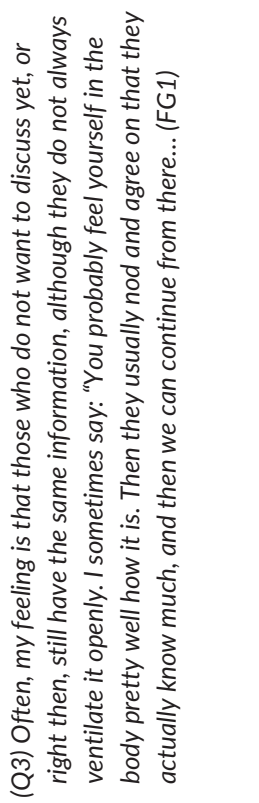 & 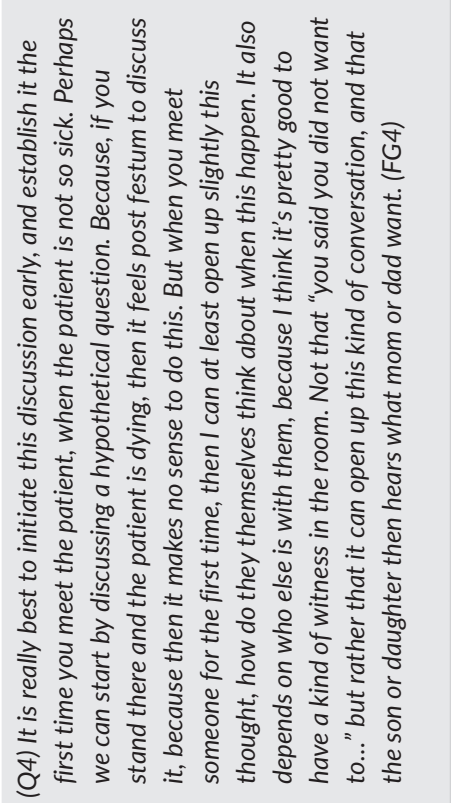 \\
\hline 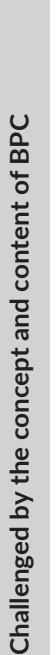 & 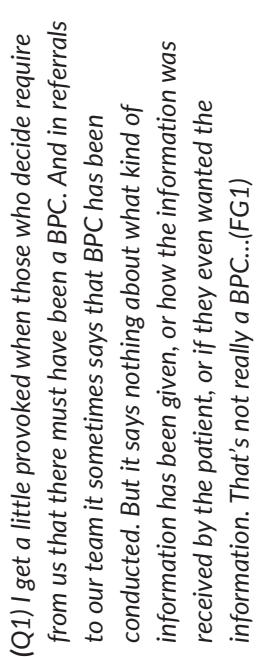 & 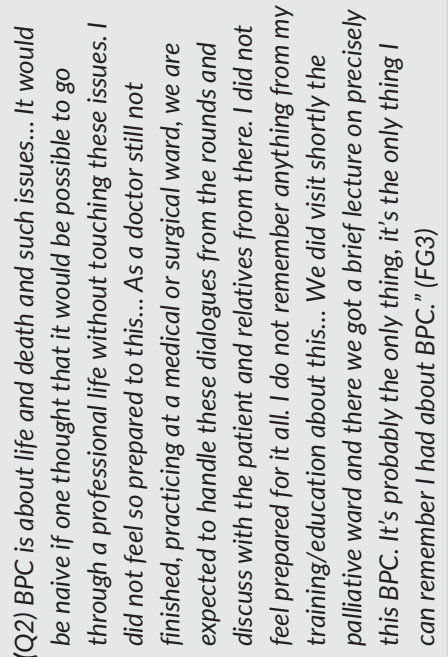 \\
\hline
\end{tabular}

contains medical information and that the content depended on the individual patient. They believed that BPC should be individually adapted to each patient. However, this was difficult to accomplish due to insufficient documentation in which information about both the content of previous discussions and the patient's reactions was lacking.

Because it addressed death, BPC was described as being unlike any other type of dialogue or information. The participants found BPC to be professionally and personally challenging, as well as demanding; discussing death with a patient was described as being a unique type of dialogue, particularly when, as new physicians, they felt unprepared for this type of communication (Q2). They expressed how discussing impending death while trying to promote meaning and hope regarding matters in life other than cures or the prolonging of life was a difficult balance that affected them on a personal level as well. The physicians found it particularly challenging when they had little professional experience with palliative care and BPC.

\section{2 | Experiences of proactive BPC}

The participants sometimes described themselves as "an informer" and someone who "provides" information during BPC. The participants described BPC as being at its best when there was a process of communication. During continuous dialogues with the patient and his/her family, information about the situation and deterioration could be communicated incrementally. The participants described this continuous communication as being proactive and being initiated when the patient was still quite unaffected by the disease, preferably after already having been offered palliative home care. When BPC was proactive, the participants said it allowed them to listen to the patient and obtain a sense of what he/she knew. They could start the dialogue from there, with regard to how the patient was coping. The participants also said that when proactive, they could pay attention to any specific fears regarding the future, e.g. fear of pain, or fear of choking to death, which could then be discussed. The participants felt that communication was most successful when information was adapted to each patient, i.e. based on how he/she seemed to be coping. The participants said that BPC sometimes gave a sense of relief to the patient and his/her family, confirming what the patient already intuitively knew (Q3). Adapting information and connecting it to previously given information was described as contributing to being on the "same level" as the patient. The participants claimed that many patients already had a realistic insight into their prognosis and the severity of their situation (Q3). When they did, it facilitated communication between the patient and the physician. Furthermore, adapting information was easier when the physicians had several years of professional experience. When BPC was proactive, it was easier to be prepared and well informed about the patient's trajectory, current situation and prognosis. Proactive BPC was sometimes initiated by the patient's cue or a question, which gave the physician an opportunity to pick up from there and continue the dialogue. Sometimes it was initiated by the physician with an open question such as: "How are you feeling today?", followed by a reflective question asking the patient to compare today to how he/she felt 2 weeks ago, for example. In other situations, the physician could ask 
the patient what he/she thought about the situation and what steps he/she wished to be taken in case of rapid deterioration. When BPC was conducted proactively, the participant could initiate a short discussion before the patient became too weak (Q4), let the patient rest for a few days and then have him/her return for a follow-up discussion. Proactive BPC was often discussed, and somewhat planned, by the palliative care team members as a group. The nurses, who had the daily contact with the patient, then reported the patient's situation and physical deterioration ahead of the BPC.

The professional team and the patient's family were both described as being an essential part of the communication process (Q4). According to the participants, proactive BPC was enabled by, and was at its best when supported by, well-functioning multidisciplinary teamwork. Support from, and close collaboration with, colleagues was described as being crucial to accomplish proactive BPC. In particular, close cooperation with the registered nurses (RNs) was emphasised because the RNs were often the professionals who best knew the patient and family. Most often, BPC was initiated by another team member's (mainly the RN's) perceptions of deterioration. Proactive BPC was described to enable consensus regarding further planning with the patient and the patient's family. The participants mentioned that sometimes BPC was even more important, and of more use, for the family than for the patient, i.e. when the patient had come to terms with the situation more than the family had, and when the patient had deteriorated at an unexpectedly fast rate or was unconscious. The participants emphasised the importance of the family being given information so that they and the professional team could work towards the same goals. However, it was sometimes difficult to help the family accept the situation of "only" end-of-life care instead of a cure or life prolongation. When BPC was proactive, there was a greater likelihood that the family was better prepared and had a realistic understanding of the situation.

\section{3 | Uncertainty affecting BPC}

Uncertainty on several levels was described as impeding BPC, especially for the physicians who were quite new within palliative care. For example, the participants described uncertainty regarding when the time was right for BPC and regarding how to conduct BPC. Reasons for feeling uncertain included a lack of experience with palliative care, a lack of experience or training regarding communication and a lack of knowledge about how to handle demanding dialogues, such as those involving dying and death. The participants also said that they were uncertain as to how to convey medical information about severe deterioration while simultaneously promoting hope (Q6). The participants expressed a fear of being wrong about the patient's medical status and of conducting unnecessary BPC. At the same time, they expressed high demands on themselves and a high level of expectation when it came to achieving successful BPC (Q5).

The participants stated that as a consequence of an uncertain prognosis and a lack of communication skills regarding issues such as death, information was often given in an acute situation near the patient's imminent death. They described this as reactive BPC and added that sometimes BPC was not initiated at all. Prognosis was particularly difficult when the patient was older and/or when the disease was not steadily progressive. A cancer diagnosis was described as "easier" to follow and easier when predicting a possible trajectory than, e.g. the diagnoses multiple sclerosis (MS) or chronic obstructive pulmonary disease (COPD) (Q6). Timing was described as one of the most difficult components to consider regarding BPC. When the "right time" was never found, BPC was not conducted. The participants said that when BPC was reactive, i.e. conducted as a reaction to the patient's sudden severe deterioration, it was difficult for the patient to express preferences or for the information to affect the family's planning constructively.

\section{5 | DISCUSSION}

\subsection{Summary of the main results}

In this study, the experiences of palliative home care physicians in terms of end-of-life BPC were explored. The results show that BPC is a concept used in discussions among professionals only and is not applied in discussions with patients. The participants in our study emphasised how important it was for BPC to be conducted proactively. In practice, however, BPC is often conducted as a reaction to the patient's sudden deterioration or is sometimes not conducted at all. As a consequence, the patient does not receive the information he/she is entitled to. Our study identifies barriers to proactive BPC. The barriers primarily concern physicians' uncertainty regarding the timing of BPC mainly due to the difficulties in prognostication regarding time of death, uncertainty of what BPC should involve and a fear of being wrong, in addition to insecurity regarding how BPC should be approached. BPC dialogues are often found to be challenging. Furthermore, our results suggest that insufficient documentation regarding previous BPC impedes proactive BPC and obstructs a continual BPC process.

\subsection{Barriers to the BPC process}

Our study shows that the physicians were uncertain when it came to the timing of BPC due to difficulties in prognostication, particularly if the patient had a diagnosis other than cancer. However, the issue of timing may be avoided if BPC is considered a process, i.e. initiated before the patient is too ill, with continuous communication following the disease trajectory. When, however, BPC is regarded as one dialogue only, the pressure on the physician to find the right time for that one and only BPC discussion increases. Furthermore, if there is only one episode of BPC, then there is a risk that the physician on duty at the point in time when BPC must be conducted is not the physician who has been providing treatment and consequently does not know the patient or his/her family. If, instead, BPC is considered a proactive process, the patient and family are given a fair chance to participate in recurrent dialogues with the same physician. This allows patients to be given an opportunity to reflect on their situation and information, return for more questions and perhaps make adjustments in their lives.

Our results show that end-of-life discussions, such as BPC, that involve death and other existential issues have the potential to also affect the physician on a personal level. This is consistent with previous 
studies showing that existential dialogues are often perceived to be demanding and difficult (Braun, Ford, Beyth, \& McCullough, 2010; Johansson \& Lindahl, 2012; Udo, Danielson, Henoch et al., 2013; Udo, Danielson, \& Melin-Johansson, 2013; Udo, Melin-Johansson, \& Danielson, 2011; Udo, Melin-Johansson, Henoch, Axelsson, \& Danielson, 2014). In our study, physicians experienced insecurity regarding what and how to communicate during BPC. The need for communication training, highlighted in our study, confirms previous studies regarding physicians' lack of communication skills (Carter et al., 2006; Evans et al., 2014; McClung, 2013; Rhondali, Burt, Wittenberg-Lyles, Bruera, \& Dalal, 2013; Syed, Almas, Naeem, Malik, \& Muhammad, 2016; Winner et al., 2016). Communication training has the potential to contribute to increased confidence in conducting demanding dialogues involving existential issues (cf. Bishop et al., 2016; Udo et al., 2014) and thus enhance the quality of care. Communication training may also compensate for sparse practical experience and help physicians feel better prepared. The physicians in our study noted that they, as physicians, cannot avoid communication with severely ill and dying patients, even if they do not work in palliative care units. Consequently, all physicians could gain from this type of communication training.

Similar to the results in the study of Nedjat-Haiem et al. (2017), physicians in our study saw themselves as being responsible for achieving informative end-of-life communication. Our study adds that the responsibility is also accompanied by their fear of being wrong, high demands on themselves and high expectations of themselves to perform well. Although our results indicate that clinical experience may compensate for the lack of education and training in communication, this is not enough to resolve communication problems (Fallowfield et al., 2002). Furthermore, every patient has a right to information and communication regardless of the physician's experience. Some physicians in our study described themselves as being an "informer", implying one-way communication. This raises the question of whether the view of being merely an informer might be a self-protective strategy. If so, reflective communication training to increase the understanding of existential issues in addition to communication may support the physician in promoting a more mutual BPC.

A third barrier to proactive BPC identified in our study, in addition to a lack of communication skills and an uncertain prognosis, concerns insufficient documentation. Currently, there may be a note in the patient's journal that BPC has occurred, but according to our results there is no further information about what has been said or how the patient reacted. Improved documentation is necessary for the care team to enable the patient's and family's involvement in end-of-life care (Lindström, Gaston-Johansson, \& Danielson, 2010). To increase continuity in care, there must also be continuity in documentation where the physician also has access to previous medical records so that information can build upon what has previously been communicated.

\section{6 | STUDY LIMITATIONS}

This study has several limitations. First, when conducting a qualitative analysis, there may be a risk of bias because of the authors' pre-existing understanding. In our analysis, this was addressed by continuous critical and reflective discussions among the authors. Furthermore, in the analytical process, there was constant movement between the different steps, ensuring that every step was firmly based on what had been expressed by the participants. It is also important to keep in mind that the focus group discussions are subjective and based on the physicians' perceived experiences and are not objective descriptions of events. The lack of ethnic diversity in this study must also be considered.

\section{7 | CONCLUSIONS}

Our results show that physicians regard BPC as a process of communication that needs to be initiated at an early stage, i.e. proactively, and that continuity in care is a prerequisite for a proactive BPC process. More detailed documentation of previously initiated BPC constitutes an important part of this process, allowing different caregivers access to the documentation and allowing them to follow the patient's trajectory. To improve high-quality end-of-life care based on a respectful process of communication, physicians' uncertainty regarding the content and timing of BPC needs to be addressed especially when the disease trajectory is difficult to predict.

\section{ACKNOWLEDGEMENTS}

We would like to thank the participants for sharing their experiences.

\section{AUTHORS' CONTRIBUTIONS}

GL and BA proposed the original idea for the project and secured funding. CU redesigned and coordinated the study and conducted the focus group interviews together with ML. CU analysed the data in discussion with $M L$, and $C U$ wrote the manuscript, which all of the authors helped revise. The final manuscript was read and approved by all of the authors.

\section{CONFLICTS OF INTEREST}

There are no conflicts of interest to declare.

\section{REFERENCES}

Andreassen, P., Neergaard, M. A., Brogaard, T., Skorstengaard, M. H., \& Jensen, A. B. (2015). The diverse impact of advance care planning: a long-term follow-up study on patients' and relatives' experiences. BMJ Supportive \& Palliative Care. https://doi.org/10.1136/ bmjspcare-2015-000886

Bishop, T. W., Gorniewicz, J., Floyd, M., Tudiver, F., Odom, A., \& Zoppi, K. (2016). Innovative patient-centered skills training addressing challenging issues in cancer communications: Using patient's stories that teach. International Journal of Psychiatry in Medicine, 51, 357-366.

Braun, U. K., Ford, M. E., Beyth, R. J., \& McCullough, L. B. (2010). The physician's professional role in end-of-life decision-making: Voices of racially and ethnically diverse physicians. Patient Education and Counseling, 80, 3-9.

Carter, C. L., Zapka, J. G., O'Neill, S., DesHarnais, S., Hennessy, W., Kurent, J., \& Carter, R. (2006). Physician perspectives on end-of-life care: 
Factors of race, specialty, and geography. Palliative \& Supportive Care, 4, 257-271.

Clayton, J. M., Butow, P. N., Arnold, R. M., \& Tattersall, M. H. (2005). Discussing end-of-life issues with terminally ill cancer patients and their careers: A qualitative study. Supportive Care in Cancer, 13, 589-599.

Clayton, J. M., Hancock, K., Parker, S., Butow, P. N., Walder, S., Carrick, S., ... Tattersall, M. H. (2008). Sustaining hope when communicating with terminally ill patients and their families: A systematic review. PsychoOncology, 17, 641-659.

Diamond, E. L., Corner, G. W., De Rosa, A., Breitbart, W., \& Applebaum, A. J. (2014). Prognostic awareness and communication of prognostic information in malignant glioma: A systematic review. Journal of NeuroOncology, 119, 227-234.

Dy, S. M., Apostol, C., Martinez, K. A., \& Aslakson, R. A. (2013). Continuity, coordination and transitions of care for patients with serious and advanced illness: A systematic review of interventions. Journal of Palliative Medicine, 16, 1-10.

Evans, N., Costantini, M., Pasman, H. R., Van den Block, L., Donker, G. A., Miccinesi, G., ... Onwuteaka-Philipsen, B. (2014). End-of-life communication: A retrospective survey of representative general practitioner networks in four countries. Journal of Pain and Symptom Management, 47, 604-619. e603.

Fallowfield, L., Jenkins, V., Farewell, V., Saul, J., Duffy, A., \& Eves, R. (2002). Efficacy of a cancer research UK communication skills training model for oncologists: A randomised controlled trial. Lancet, 359, 650-656.

Horlait, M., Chambaere, K., Pardon, K., Deliens, L., \& Van Belle, S. (2016). What are the barriers faced by medical oncologists in initiating discussion of palliative care? A qualitative study in Flanders, Belgium. Supportive Care in Cancer, 24, 3873-3881. https://doi.org/10.1007/s00520-016211-5

Jamieson, L., \& Williams, L. M. (2003). Focus group methodology: Explanatory notes for the novice nurse researcher. Contemporary Nurse: A Journal for the Australian Nursing Profession, 14, 271-280.

Johansson, K., \& Lindahl, B. (2012). Moving between rooms-moving between life and death: Nurses' experiences of caring for terminally ill patients in hospitals. Journal of Clinical Nursing, 21, 2034-2043.

Krippendorff, K. (2013). Content analysis: An introduction to its methodology, 3rd edn. London: Sage Publications.

Laryionava, K., Heussner, P., Hiddemann, W., \& Winkler, E. C. (2015). Framework for timing of the discussion about forgoing cancer-specific treatment based on a qualitative study with oncologists. Supportive Care in Cancer, 23, 715-721.

Lindström, I., Gaston-Johansson, F., \& Danielson, E. (2010). Patients' participation in end-of-life care: Relations to different variables as documented in the patients' records. Palliative \& Supportive Care, 8, 247-253.

Lundquist, G., Rasmussen, B. H., \& Axelsson, B. (2011). Information of imminent death or not: Does it make a difference? Journal of Clinical Oncology, 29, 3927-3931.

McClung, J. A. (2013). End-of-life care in the treatment of advanced heart failure in the elderly. Cardiology in Review, 21, 9-15.

Miccinesi, G., Bianchi, E., Brunelli, C., \& Borreani, C. (2012). End-of-life preferences in advanced cancer patients willing to discuss issues surrounding their terminal condition. European Journal of Cancer Care, 21, 623-633.

Morgan, D. L. (1997). Focus groups as qualitative research, 2nd edn. London: Sage Publications.

Nedjat-Haiem, F. R., Carrion, I. V., Gonzalez, K., Ell, K., Thompson, B., \& Mishra, S. I. (2017). Exploring health care providers' views about initiating end-of-life care communication. American Journal of Hospice and Palliative Care, 34, 308-317.

Neergaard, M. A., Jensen, A. B., Sondergaard, J., Sokolowski, I., Olesen, F., Vedsted, P. (2011). Preference for place-of-death among terminally ill cancer patients in Denmark. Scandinavian Journal of Caring Sciences, 25, 627-636.

Pfeil, T. A., Laryionava, K., Reiter-Theil, S., Hiddemann, W., \& Winkler, E. C. (2015). What keeps oncologists from addressing palliative care early on with incurable cancer patients? An active stance seems key. Oncologist, 20, 56-61.

Rhondali, W., Burt, S., Wittenberg-Lyles, E., Bruera, E., \& Dalal, S. (2013). Medical oncologists' perception of palliative care programs and the impact of name change to supportive care on communication with patients during the referral process. A qualitative study. Palliative \& Supportive Care, 11, 397-404.

Schou-Andersen, M., Ullersted, M. P., Jensen, A. B., \& Neergaard, M. A. (2016). Factors associated with preference for dying at home among terminally ill patients with cancer. Scandinavian Journal of Caring Sciences, 30, 466-476.

Syed, A. A., Almas, A., Naeem, Q., Malik, U. F., \& Muhammad, T. (2016). Barriers and perceptions regarding code status discussion with families of critically ill patients in a tertiary care hospital of a developing country: A cross-sectional study. Palliative Medicine, 31, 147-157.

The Swedish Government Official Report (SOU 2001:6). Retrieved from http://www.regeringen.se/contentassets/9b252638652e497ab0e16f66a0a54cf9/doden-angar-oss-alla (Accessed September 20 2016).

The Swedish National Board of Health and Welfare (2007). National guidelines on breast, colorectal, and prostatic cancer. [in Swedish]. Stockholm: the Swedish National Board of Health and Welfare.

The Swedish Register for Palliative Care (2007). Retrieved from http:// www.palliativ.se (Accessed August 21 2016).

Udo, C., Danielson, E., Henoch, I., \& Melin-Johansson, C. (2013). Surgical nurses' work-related stress when caring for severely ill and dying patients in cancer after participating in an educational intervention on existential issues. European Journal of Oncology Nursing, 17, 546-553.

Udo, C., Danielson, E., \& Melin-Johansson, C. (2013). Existential issues among nurses in surgical care - A hermeneutical study of critical incidents. Journal of Advanced Nursing, 69, 569-577.

Udo, C., Melin-Johansson, C., \& Danielson, E. (2011). Existential issues among health care staff in surgical cancer care - Discussions in supervision sessions. European Journal of Oncology Nursing, 15, 447-453.

Udo, C., Melin-Johansson, C., Henoch, I., Axelsson, B., \& Danielson, E. (2014). Surgical nurses' attitudes towards caring for patients dying of cancer - A pilot study of an educational intervention on existential issues. European Journal of Cancer Care, 23, 426-440.

Walczak, A., Butow, P. N., Bu, S., \& Clayton, J. M. (2016). A systematic review of evidence for end-of-life communication interventions: Who do they target, how are they structured and do they work? Patient Education and Counseling, 99, 3-16.

Wibeck, V. (2010). Fokusgrupper: Om fokuserade gruppintervjuer som undersökningsmetod [Focus groups: Focused group interviews as a research method]. Lund, Sweden: Studentlitteratur.

Winner, M., Wilson, A., Yahanda, A., Gani, F., \& Pawlik, T. M. (2016). Cancer surgeons' attitudes and practices about discussing the chance of operative "cure". Surgery, 160, 1619-1627. https://doi.org/10.1016/j.surg. 2016.06.009

World Health Organization (WHO) (2002). Definition of palliative care, 2nd edn. Geneva: World Health Organization.

Worldwide Palliative Care Alliance, WHO. (2014). Global atlas of palliative care at the end of life. Retrieved from http://www.who.int/nmh/ Global_Atlas_of_Palliative_Care.pdf (Accessed August 18 2016).

Wright, A. A., Zhang, B., Ray, A., Mack, J. W., Trice, E., Balboni, T., ... Prigerson, H. G. (2008). Associations between end-of-life discussions, patient mental health, medical care near death, and care-giver bereavement adjustment. Journal of the American Medical Association, 300, 1665-1673.

How to cite this article: Udo C, Lövgren M, Lundquist G, Axelsson B. Palliative care physicians' experiences of end-of-life communication: A focus group study. Eur J Cancer Care. 2017;e12728. https://doi.org/10.1111/ecc.12728 